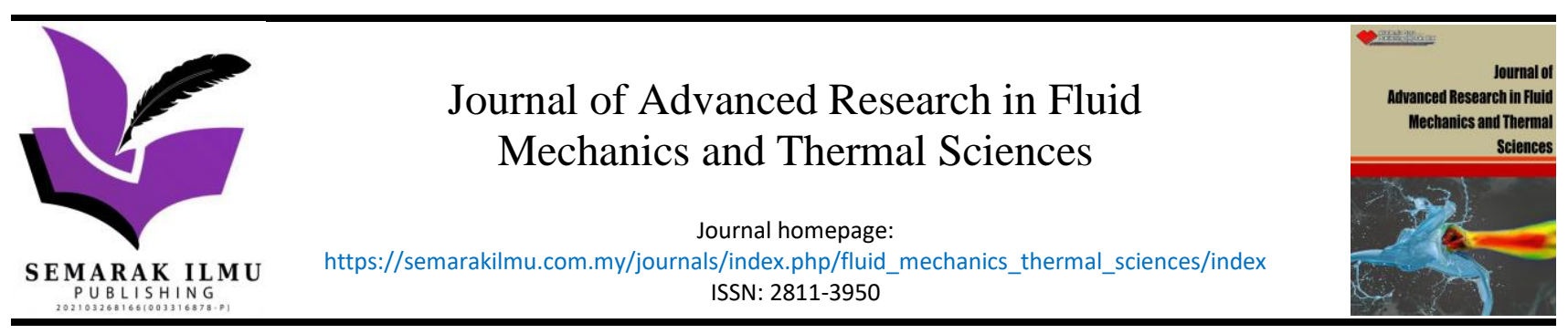

\title{
Performance of Electrostatic Precipitator as Air Cleaner in Water Production Process from Humid Air
}

\author{
Samsudin Anis ${ }^{1,}{ }^{*}$, Andrika Hilman Hanif ${ }^{1}$, Ahmad Mustamil Khoiron ${ }^{1}$, Adhi Kusumastuti ${ }^{2}$ \\ Department of Mechanical Engineering, Universitas Negeri Semarang, Kampus Sekaran, Gunungpati, 50229 Semarang, Indonesia \\ Faculty of Engineering, Universitas Negeri Semarang, Kampus Sekaran, Gunungpati, 50229 Semarang, Indonesia
}

ARTICLE INFO

\section{Article history:}

Received 28 July 2021

Received in revised form 3 December 2021

Accepted 25 December 2021

Available online 20 January 2022

\section{Keywords:}

Electrostatic precipitator; particle collection efficiency; humid air; atmospheric water maker; water quality

\section{ABSTRACT}

Humid air as a source of water can be utilized by using a condensation system called the Atmospheric Water Maker (AWM) in order to overcome the problem of limited drinking water supply. However, to maintain water quality and production capacity, the AWM requires an air filtration system with minimum flow resistance. In this work, an electrostatic precipitator (ESP) was used as an air filter for AWM application. Thus, this study aimed to investigate the performance of ESP in terms of particle collection efficiency and water quality produced by AWM. In order to evaluate the performance of ESP, wire to cylinder type ESP was designed and three experimental activities were performed i.e., smoke filtration test, dust filtration experiment, and AWM water quality assessment. The performance of ESP was studied at various voltages ranging from $5.8 \mathrm{kV}$ to $9.7 \mathrm{kV}$ and two wire mesh sizes. The results showed soot particles were successfully removed by the ESP for all applied voltages with both $1 \mathrm{~mm}$ and $4 \mathrm{~mm}$ wire mesh. The effect of ESP voltage could be observed in dust filtration experiments in which the particle collection efficiency increases with the increase of voltage. The highest particle collection efficiency was observed at a voltage of $9.7 \mathrm{kV}$ with a wire mesh of $1 \mathrm{~mm}$. The results also showed that the use of ESP for AWM application offered a positive effect on the quality of condensed water in which the water physical and chemical properties satisfy the WHO standard for drinking water.

\section{Introduction}

The availability of drinking water with its role as a basic need of the human body must be ensured. However, serious problems of the existences of various cases of drought and water pollution affect the availability of clean drinking water. Thus, alternative water sources are needed to maintain the availability of clean and potable water. Among the sources of water is the atmosphere which contains a lot of water thus being an alternative source of drinking water. Beysens and Milimouk [1] stated that the earth's atmosphere contains $12,800 \mathrm{~km}^{3}$ of water, $98 \%$ of which is water vapor and $2 \%$ in liquid forms such as water droplets in clouds and fog. One of the equipment that can be utilized to harvest water from the atmosphere is the Atmospheric Water Maker (AWM) with a cooling or

\footnotetext{
${ }^{*}$ Corresponding author.

E-mail address: samsudin_anis@mail.unnes.ac.id
}

https://doi.org/10.37934/arfmts.91.1.129139 
refrigeration system. This system works by cooling the air stream so that a condensation process occurs to produce water from the atmosphere [2]. It should be noted that the air in the atmosphere contains various harmful pollutants including particulate matter and gaseous pollutants that can contaminate the resulting condensate water. Furthermore, the interior air quality of buildings and office environments with enclosed spaces has a high dust concentration due to the continuous movement that occurs every day [3]. This situation will worsen if buildings create a canyon-like environment known as a street canyon, which restricts air ventilation inside [4]. For this reason, the humid air must be cleaned by filtration prior to the condensation process. On the other hand, the filtration process is generally beneficial because it ensures the quality of the produced water. However, the filtration process can also be detrimental to the system because it inhibits air stream, which in turn reduces the quantity of water produced. Thus, an air filtration system that is not only able to clean the air but also maintains the condensate water production capacity is needed.

Various air filtration devices that can remove particles from the air have been introduced. The devices are categorized into two type's namely mechanical filters and electronic air cleaners [5]. The effectiveness of mechanical filters, however, drops over time since mechanical air filters work by trapping particulates in the filter material that is hard to be cleaned while electronic filters work by drawing particles into the collector using static electricity, which is relatively easy to be cleaned. In addition, while these filters are relatively more expensive than mechanical filters, they also tend to be more effective. One of the electronic filters is electrostatic precipitator (ESP). ESP is a separation process device used to control particulate emissions. ESP is widely used for the control of air and gas pollutants in a variety of fields including power plants, urban waste incinerators, as well as heating, ventilation, and air conditioning (HVAC) systems [6]. ESP is chosen as the air filtration system because of its high particle collection efficiency and minimum flow resistance [7].

Several studies that examine the use of ESP as a particle emission cleaner have been conducted [5]. There are several factors that affect ESP performance such as types of collecting electrodes, geometric, electrode material, air/gas flow rate, collector voltage, etc. The effect of voltage on particle collection efficiency has been investigated in previous studies such as that conducted by Porteiro et al., [8]. This research estimated the dust collection efficiency of small-scale ESP using simulation software and found that the increase in voltage causes an increase in particle collection efficiency. Xiao et al., [9] conducted an experimental study and confirmed that the efficiency of particle collection increases rapidly with increasing ESP voltage. The two studies provide important information that the results of the simulation-based study are consistent with the experimentalbased study that the ESP voltage has a major effect on the particle collection efficiency. Furthermore, the effect of electrode geometry parameters on ESP performance has also been studied by Sander et al., [10]. They compared the use of wire and spike-wire as discharge electrodes on ESP performance and found that ESP performance is superior with spike-wire compared to wire electrodes. The results of this study were corroborated by He and Dass [11] who argued that the electrode geometry parameter is the fourth parameter that has the most influence on ESP performance. This shows that electrode geometry has an important role in improving air quality.

Based on the above description, although the application of ESP as an air purifier has been widely reported in the literature and the performance of ESP has also been studied in various parameters and operating conditions, however, most of these studies generally use a wire to plate type ESP in which the plate serves as the collecting electrode. In addition, it is difficult to obtain information that assesses other sequential impacts of the application of ESP, especially in the case of water production from humid air. Therefore, it is very important to study the presence of ESP in the process of water production from humid air. Thus, this study aims to design and to investigate the presence of ESP as the effect of collector voltage and discharge electrodes geometry on particle collection efficiency and 
water quality produced by AWM. It should be noted that instead of the wire to plate type, this work used a wire to cylinder type ESP.

\section{Methodology}

In order to examine the performance of ESP for AWM application, wire to cylinder type ESP has been designed and fabricated as shown in Figure 1. It was made of nine cylinders with a size of 58 $\mathrm{mm}$ diameter and $158 \mathrm{~mm}$ length. To ensure that the intake air can flow through the inside of each cylinder, the gaps between the cylinders have been blocked in such away. Wire mesh type was used as the discharge electrode positioned on the inlet airside, while aluminum foil was used as the collecting electrode placed along the inner wall surface of the cylinders. The designed ESP has a maximum voltage of $9.7 \mathrm{kV}$.
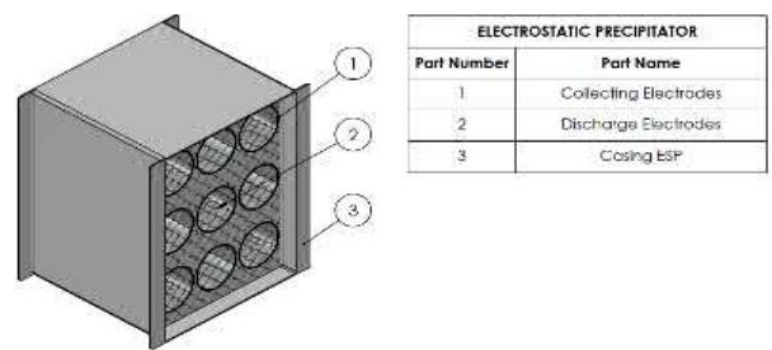

Fig. 1. Schematic design of ESP

Three experimental steps were applied to evaluate the performance of ESP for AWM application that could be described in the following section.

\subsection{Smoke Filtration Test}

The experimental setup and photograph of smoke filtration test are illustrated in Figure 2. It consists of a smoke generator, ESP, test section, and a high-speed camera. The test section was equipped with a black wall box and a light bulb to facilitate the smoke capture process using a camera. The test was performed by burning wastepaper as a smoke source in the smoke chamber located at the bottom side of the test rig. The smoke then naturally flowed through ESP and test section at the top side.

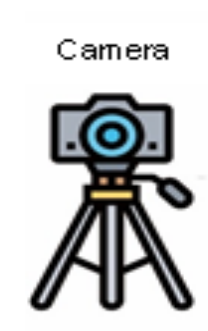

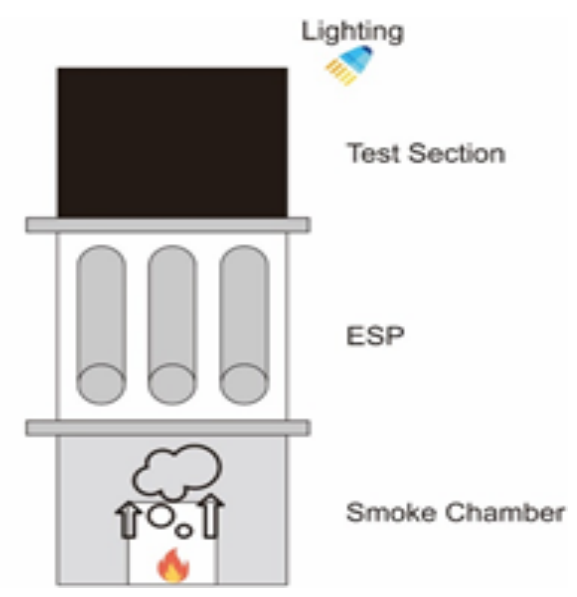

(a)

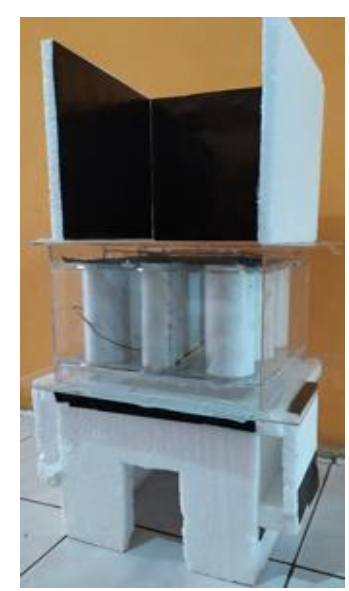

(b)

Fig. 2. Experimental setup scheme (a) and photograph (b) of ESP for smoke filtration experiment 
In this study, the smoke was visually observed and qualitatively analyzed based on the captured smoke before and after ESP was activated. The experiments were performed at various voltages of $5.8 \mathrm{kV}$ to $9.7 \mathrm{kV}$ and wire meshes of $1 \mathrm{~mm}$ and $4 \mathrm{~mm}$.

\subsection{Dust Filtration Experiment}

The experimental setup and photograph of ESP for dust filtration experiment are shown in Figure 3. It consists of $1^{\text {st }}$ test section, ESP, $2^{\text {nd }}$ test section, and a suction blower. Dust sensors were also used in each test section to measure dust density and linked to laptop for dust quantification. The test was carried out by sprinkling loose powder as a substitute of dust in the $1^{\text {st }}$ test section. The loose powder then flowed through the ESP, $2^{\text {nd }}$ test section, and flowed out through the suction blower. Initial dust concentration was $0.5 \mathrm{mg} / \mathrm{m}^{3}$ on average in each experimental activity. Air velocity for each experiment was set at $3 \mathrm{~m} / \mathrm{s}$.

In this study, dust amount of loose powder was measured using dust sensors. ESP dust collection efficiency was evaluated based on the amount of dust before and after ESP was activated. The experiments were performed at various voltages of $5.8 \mathrm{kV}$ to $9.7 \mathrm{kV}$ and wire meshes of $1 \mathrm{~mm}$ and 4 $\mathrm{mm}$.

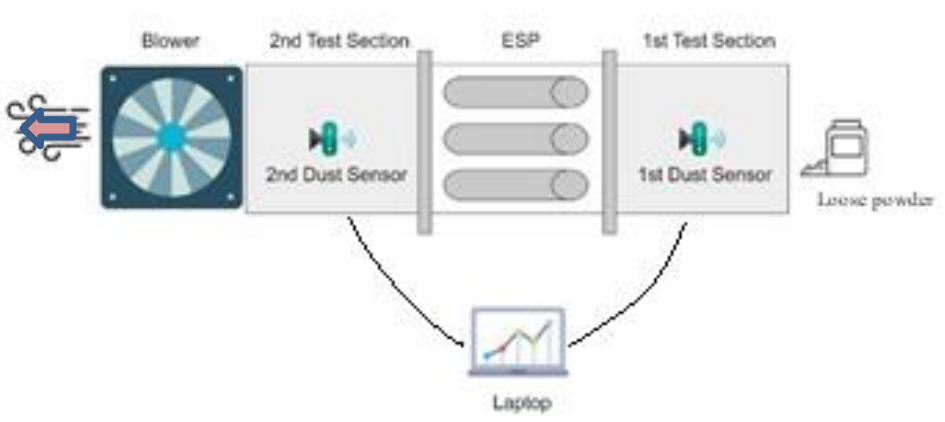

(a)

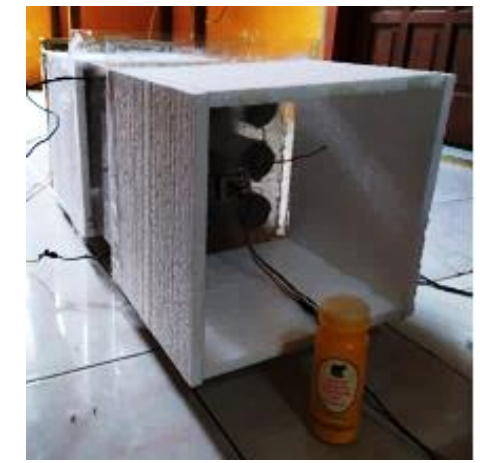

(b)

Fig. 3. Experimental setup scheme (a) and photograph (b) of ESP for dust filtration experiment

\subsection{AWM Water Quality Assessment}

The experimental apparatus scheme of water production from humid air using AWM with ESP as air filter is illustrated in Figure 4. It mainly consists of an ESP, humid air condensation system, suction blower, and a condensed water collection tank. AWM used in this work has a maximum input power of $400 \mathrm{~W}$ that is capable to produce water of 23 liters per day. It should be noted that ESP was the only applied filtration device in this process in order to assess filtration capability of ESP, whereas other types of auxiliary purification devices are removed from AWM. The experiments were carried out at two voltages of $5.8 \mathrm{kV}$ with wire mesh of $4 \mathrm{~mm}$ and $9.7 \mathrm{kV}$ with wire mesh of $1 \mathrm{~mm}$. Each experiment was conducted for 3 hours. 


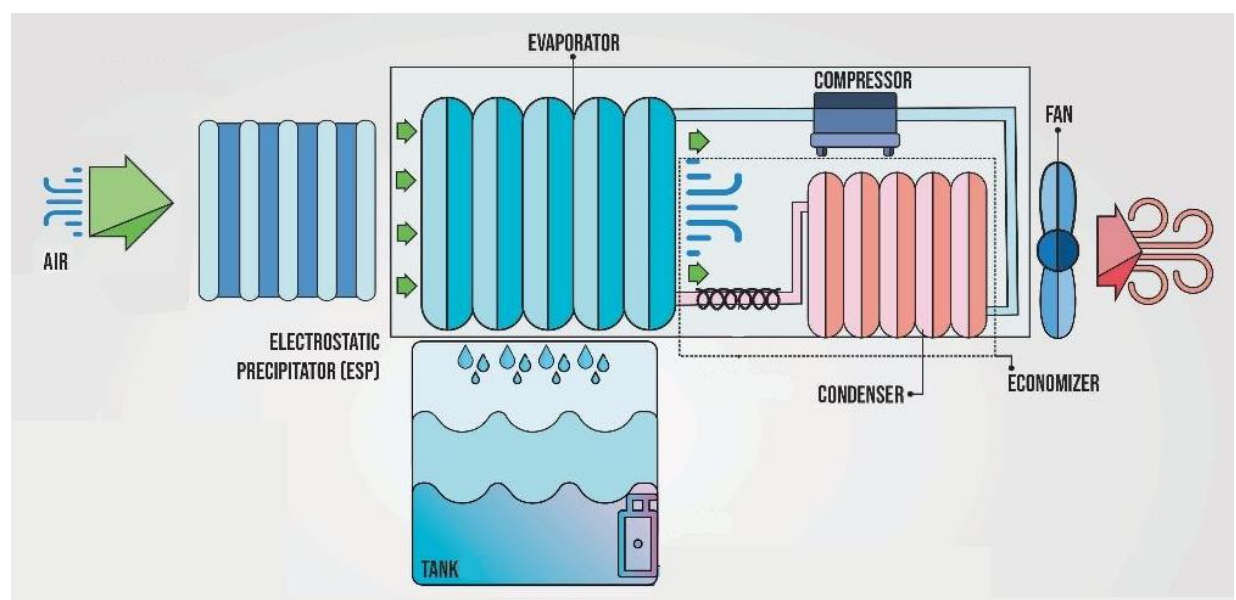

Fig. 4. Experimental setup scheme of water production from humid air using AWM with ESP as air filter

After each experiment, the sample of condensed water collected in the tank was taken for drinking water quality analysis purposes. Water quality analysis in this study refers to the water quality standards regulated by World Health Organization [12], WHO Standard 2017 and Ministry of Health of Republic of Indonesia [13] regulation No. 492/MENKES/PER-IV/2010. Water quality parameters used in this work consisted of physicals and chemicals properties.

\section{Results}

\subsection{Smoke Filtration Test}

In this study, the smoke was visually observed and analyzed qualitatively based on the captured smoke before and after ESP was activated. Figure 5 depict photograph of smoke condition within the chamber before and after activation of ESP at various applied voltages. As shown, when the ESP was switched off, smoke particles moving through the system were clearly observed visible in the test section. A different situation was encountered when the ESP was turned on in which the smoke particles were completely observed invisible in the test section. This condition was found for all applied voltages with both $1 \mathrm{~mm}$ and $4 \mathrm{~mm}$ wire mesh. 

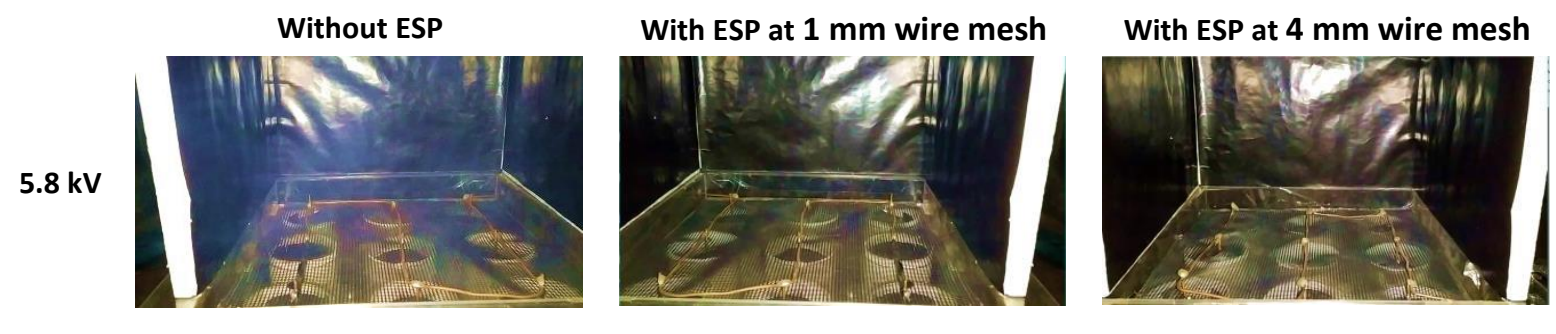

$7.7 \mathrm{kV}$
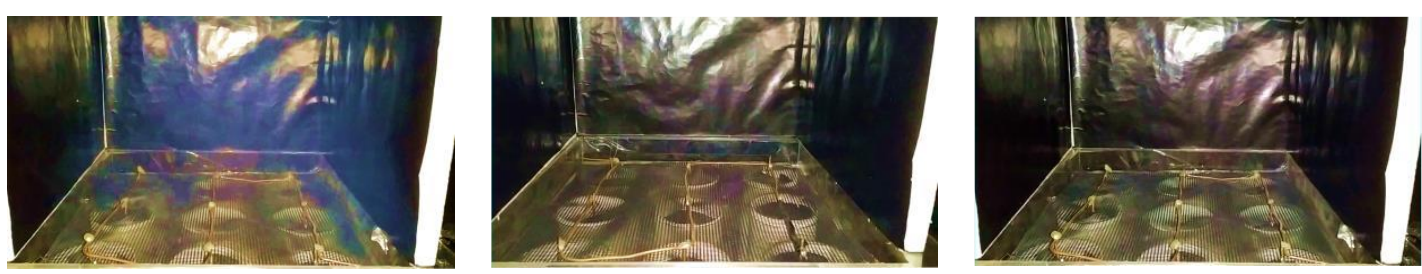

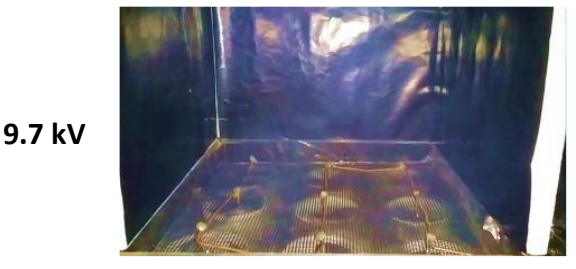

Without ESP

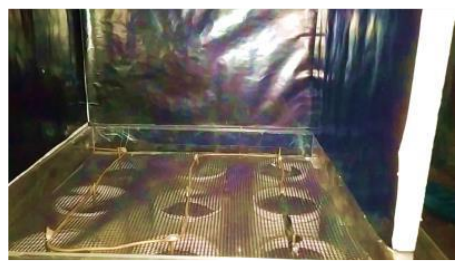

With ESP at $1 \mathrm{~mm}$ wire mesh

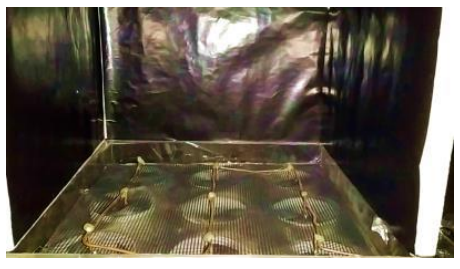

With ESP at $4 \mathrm{~mm}$ wire mesh

Fig. 5. Photograph of smoke particle condition at test section before ESP activated and after ESP activated at various applied voltages and wire meshes

The above results showed that the particles are charged in the pre-charged of wire mesh and then collected at the collecting electrode. As it is known that ESP uses the principle of attractive force between charged particles and the collector electrodes of the particles so that it is effective in capturing fine particles such as smoke particles from the air stream. The particles passing through the precipitator are given a negative electrical charge by being forced through the discharge electrodes of wire mesh, in which the gas ions flow. After the particles have been negatively charged, it is forced into the positively charged cylinders as the collecting electrodes.

\subsection{Dust Filtration Experiment}

Figure 6 shows the effect of voltage variation on the collection efficiency of the ESP at both $1 \mathrm{~mm}$ and $4 \mathrm{~mm}$ wire meshes. It should be noted that loose powder that has a larger particle size than smoke particles was employed in this experiment as a substitute for dust. In addition, the experiments also use a very high initial concentration of dust of around $500 \mu \mathrm{g} / \mathrm{m}^{3}$ in order to obtain clearer information regarding the potential of the designed ESP to capture particles from extreme dirty air conditions. As shown, the designed ESP was able to remove dust particles from the air under the investigated condition. 


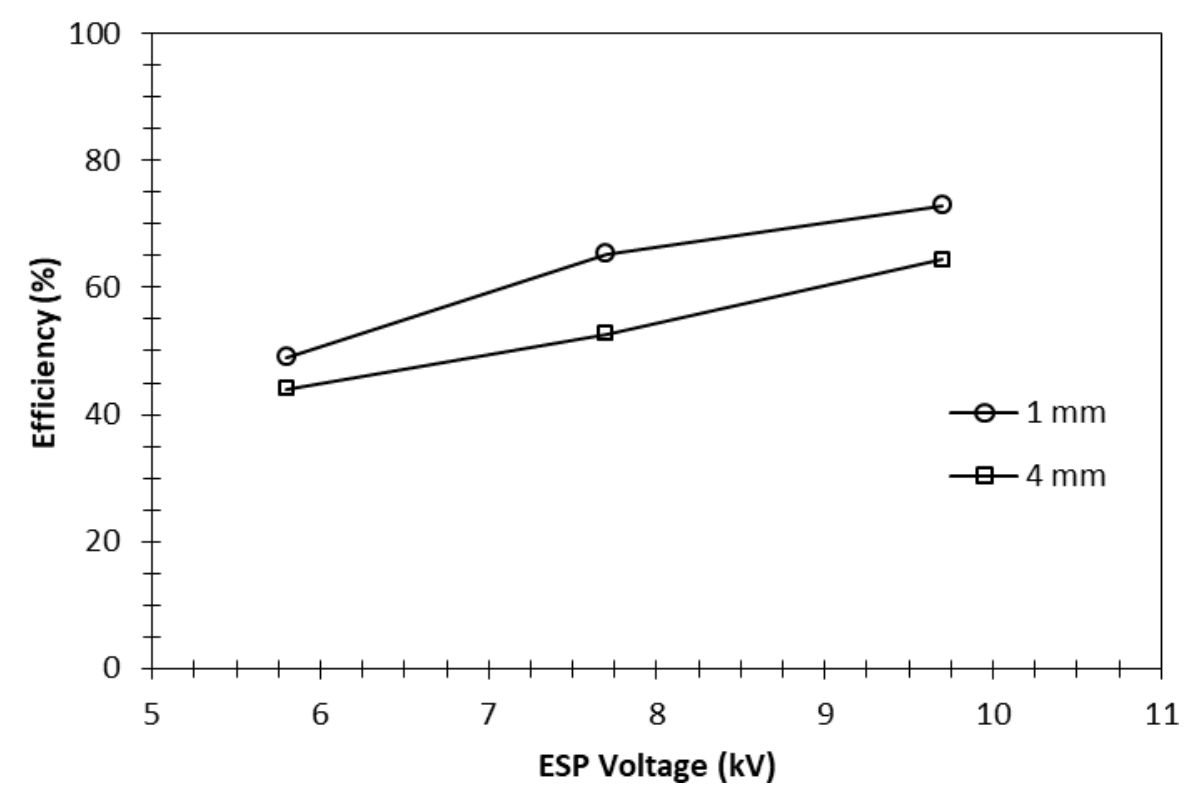

Fig. 6. Effect of ESP voltage on particle collection efficiency at two different wire meshes

The results showed that the highest particle collection efficiency was obtained at a voltage of 9.7 $\mathrm{kV}$ with $1 \mathrm{~mm}$ wire mesh. On the other hand, the lowest particle collection efficiency was obtained at a voltage of $5.8 \mathrm{kV}$ with $4 \mathrm{~mm}$ wire mesh. Based on these results, it can be observed from the figures that the collection efficiency of the particles increased with the increase of the applied voltage. This indicated that ESP filtration relies on the attractive forces between the charged particles. The strength of the attractive forces between these charged particles depends on the magnitude of the electric field and the released charge. Furthermore, it is known that the strength of the electric field formed is directly proportional to the applied voltage. This means that a higher voltage provides a stronger attractive force between the charged particles, resulting in higher particle collection efficiency. This phenomenon was also experienced in a previous study that the efficiency of ESP depends on the voltage [14]. He and Dass [11] also state that voltage is the most influential parameter to the ESP performance.

Figure 6 also points out that there is a tendency for denser wire mesh to provide higher particle collection efficiencies compared to the other one. Wire mesh of $1 \mathrm{~mm}$ has a larger discharge electrode area than wire mesh of $4 \mathrm{~mm}$. A uniform electric field could be formed if the electrode dimensions are larger than the distance between the electrodes. This shows that the larger discharge electrode dimensions lead to the greater electric field. Therefore, it is important to accommodate the distance between the electrodes to produce a uniform electric field. This means that the larger the electrode dimensions, the wider the electric field produced. The wider electric field causes the discharge of impurities to become intense, resulting in an increase in the efficiency of air filtration. More efficient air filtration can collect dust particles and reduce smoke density better. The results are in line to the study conducted by Sander et al., [10] that compares the performance of ESP using wire as discharge electrodes with the performance of ESP using spiked wire as discharge electrodes. They found that ESP with spiked wire as discharge electrodes performs better due to it has a wider surface area than wire. It can produce a wider uniform electric field and produce greater filtration efficiency. Moreover, He and Dass [11] stated that the geometry of discharge electrodes is the fourth most influential parameter in determining air filtration efficiency.

Based on the above results, the designed ESP offered good particle collection efficiency at relatively low voltages operation compared to others including wire-to-plat ESP type. For instance, 
particles of 1 and $2.5 \mu \mathrm{m}$ could be reduced by $58 \%$ and $76 \%$, respectively with the use of electrostatic filters [15]. Zhang et al., [16] reported that the ESP collection efficiencies of about $50-80 \%$ could be achieved by applying voltages of $11-15 \mathrm{kV}$ at a dust concentration of $300 \mathrm{mg} / \mathrm{m}^{3}$. Pirhadi et al., [17] also found that ESP collection efficiencies of more than $80 \%$ could be obtained at $12 \mathrm{kV}$ for particles sizes of $0.015-2.5 \mu \mathrm{m}$.

\subsection{AWM Water Quality Assessment}

Table 1 shows the physical properties of water produced from the atmospheric water maker used in this work. The table provided a comparison of water quality based on physical properties without and with the use of ESP. Two ESP operating conditions were employed, namely, the ESP operated at $5.8 \mathrm{kV}$ with $4 \mathrm{~mm}$ wire mesh and one operated at $9.7 \mathrm{kV}$ with $1 \mathrm{~mm}$ wire mesh. The two conditions represent the ESP with the lowest and the highest efficiencies, respectively, as shown in Figure 6.

\section{Table 1}

Physical properties of water produced by AWM

\begin{tabular}{llllll}
\hline Parameter & Unit & $\begin{array}{l}\text { Without } \\
\text { ESP }\end{array}$ & $\begin{array}{l}\text { ESP } \\
5.8 \mathrm{kV} ; 4 \mathrm{~mm}\end{array}$ & $9.7 \mathrm{kV} ; 1 \mathrm{~mm}$ & $\begin{array}{l}\text { Maximum } \\
\text { allowable levels }^{*}\end{array}$ \\
\hline Odor & - & Odorless & Odorless & Odorless & Odorless \\
Taste & - & Tasteless & Tasteless & Tasteless & Tasteless \\
Color & TCU & 7 & 0 & 0 & 15 \\
Turbidity & NTU & 0.74 & 0.58 & 0.59 & 5 \\
$\begin{array}{l}\text { Total Dissolved Solids } \\
\text { (TDS) }\end{array}$ & $\mathrm{mg} / \mathrm{l}$ & 47.2 & 17.14 & 136.1 & 500 \\
\hline
\end{tabular}

${ }^{*}$ Referring to the WHO Standard 2017 and Indonesian Regulatory Standard for drinking water [12,13]

It could be observed from the table that the quality of water produced from AWM, in view of physical properties, generally complies the WHO standard and the regulation of the Ministry of Health of Republic of Indonesia regarding the requirements and control of drinking water quality, even without using ESP. The color and turbidity of water can be significantly reduced by implementing ESP for both used configurations. Interestingly, the resulting water has become completely colorless at zero TCU. In addition, the content of total dissolved solids (TDS) in water can also be significantly reduced, except for ESP with a high voltage of $9.7 \mathrm{kV}$ and $1 \mathrm{~mm}$ wire mesh. The result showed that at a higher voltage of $9.7 \mathrm{kV}$ with a denser wire mesh of $1 \mathrm{~mm}$, the TDS content increased quite high even though the amount is still far below the maximum allowable limit. One of the contributing factors is the possibility of degradation of the electrode material when used at high voltages. In addition, particle re-entrainment or the re-entry of particles collected in the collecting electrodes could also be a cause of the increase of TDS. Particle re-entrainment occurs because the shear forces from the fluid flow may attract particles that have adhered to the separation wall back into the free flow [18]. Particle re-entrainment can be caused by the type of collecting electrode, geometry, and operating conditions such as collector voltage and airflow rate $[19,20]$.

Table 2 tabulates the chemical properties of water produced from AWM used in this work. As with the preceding table, this table also provides comparative information on water quality in terms of chemical properties for experiments without and using ESP. 


\section{Table 2}

Chemical properties of water produced by AWM

\begin{tabular}{llllll}
\hline Parameter & Unit & $\begin{array}{l}\text { Without } \\
\text { ESP }\end{array}$ & $\begin{array}{l}\text { ESP } \\
5.8 \mathrm{kV} ; 4 \mathrm{~mm}\end{array}$ & $9.7 \mathrm{kV} ; 1 \mathrm{~mm}$ & $\begin{array}{l}\text { Maximum allowable } \\
\text { levels }\end{array}$ \\
\hline Arsenic & $\mathrm{mg} / \mathrm{l}$ & 0 & 0 & 0 & 0.01 \\
Fluoride (F) & $\mathrm{mg} / \mathrm{l}$ & 0 & 0.07 & 0 & 1.5 \\
Chromium & $\mathrm{mg} / \mathrm{l}$ & 0.01 & 0.01 & 0.02 & 0.05 \\
Nitrate & $\mathrm{mg} / \mathrm{l}$ & 5.31 & 6.64 & 6.2 & 50 \\
Nitrite & $\mathrm{mg} / \mathrm{l}$ & 0.63 & 0.53 & 0.95 & 3 \\
Aluminum (Al) & $\mathrm{mg} / \mathrm{l}$ & 0.011 & 0.014 & 0.009 & 0.2 \\
Sulfate $\left(\mathrm{SO}_{4}\right)$ & $\mathrm{mg} / \mathrm{l}$ & 0 & 0 & 0 & 250 \\
Copper $(\mathrm{Cu})$ & $\mathrm{mg} / \mathrm{l}$ & 0.07 & 0.05 & 0.02 & 2 \\
Cyanide & $\mathrm{mg} / \mathrm{l}$ & 0.001 & 0.005 & 0.003 & 0.07 \\
Iron (Fe) & $\mathrm{mg} / \mathrm{l}$ & 0.03 & 0.06 & 0.01 & 0.3 \\
Hardness (CaCO & $\mathrm{mg} / \mathrm{l}$ & 16.2 & 13.2 & 115.4 & 500 \\
Chloride $(\mathrm{Cl})$ & $\mathrm{mg} / \mathrm{l}$ & 0 & 0.5 & 0.5 & 250 \\
Manganese $(\mathrm{Mn})$ & $\mathrm{mg} / \mathrm{l}$ & 0.1 & 0.1 & 0 & 0.4 \\
Zinc & $\mathrm{mg} / \mathrm{l}$ & 0.48 & 0.15 & 0.25 & 3 \\
pH & - & 7.54 & 7.73 & 7.22 & $6.5-8.5$ \\
\hline
\end{tabular}

${ }^{*}$ Referring to the WHO standard 2017 and Indonesian Regulatory Standard for drinking water [12,13]

It could be observed from Table 2 that in general the chemical quality of water produced from AWM also complies the WHO standard and the regulation of the Ministry of Health of Republic of Indonesia regarding the requirements and control of drinking water quality, even without the use of ESP. This showed that the surrounding humid air as a source of producing water through the condensation process is of good quality during the experiments. The results also showed that the application of ESP was able to reduce the content of several chemicals such as copper, manganese, and iron. In addition, high-voltage ESP with denser wire mesh tended to give better results than lowvoltage ESP with sparser wire mesh. This indicated that the use of higher voltages can reduce the level of some pollutants contained in the air stream. The result is consistent with the preceding obtained results given in Figure 6 . This is also in line with the previous literature reported by Porteiro et al., [8] and Dramane et al., [21] that an increase in voltage leads to an increase in ESP particle collection efficiency. As a result, the quality of humid air that will be condensed is better, generating clearer and more potable water.

Although ESP appeared to have promising performance as air filtration for AWM application, however, there are still some chemicals that experience an increase in content after the use of ESP as shown in the related table. One of the parameters that have experienced a tremendous increase is water hardness $\left(\mathrm{CaCO}_{3}\right)$. This condition was encountered when ESP operated at a high voltage of $9.7 \mathrm{kV}$ with a denser wire mesh of $1 \mathrm{~mm}$. It was found that the water hardness rose about seven times from the experiment without the utilization of ESP even though the value is still far below the maximum allowable levels of WHO regulation. This might occur for some reasons such as ESP electrode material selection and geometry issues, as well as ESP fabrication process issue. The degradation of ESP material will potentially take place when the ESP is operated at high voltages as previously described.

Deteriorating water quality of AWM at the highest ESP voltage can also be caused by the release of ozone which increases with the increase of voltage. The negative polarity of discharge electrodes and the increase in voltage without an adequate size of discharge electrodes can cause the release of ozone [22]. The release of ozone can initiate reactions with organic compounds that produce fine particles, oxidation products, and free radicals [23]. This impacts not only an increase in water hardness but also the total dissolved solids content in the water. 
The above descriptions provide valuable information that ESP performance can be improved not only using high voltages but also by utilizing a denser wire mesh. In addition, to get good results, the ESP needs to be designed in such a way that it does not adversely affect the filtration results of impurities in the air stream. In the case of humid air filtration for AWM applications, low voltage of ESP is likely to be good enough at cleaning up impurities when the content of ambient air pollutants is within normal limits.

\section{Conclusions}

Wire to cylinder type ESP has been successfully designed and examined for humid air filtration in AWM application. The designed ESP was capable in capturing soot particles. The results also found that higher ESP voltages provided better particle collection efficiency. Likewise, denser wire mesh also tended to be better at imparting a negative electric charge to the particles thereby contributing to the increase of particle collection at the collecting electrodes. Under the investigated condition, the highest particle collection efficiency was found at ESP voltage of $9.7 \mathrm{kV}$ with wire mesh of $1 \mathrm{~mm}$. The designed ESP also provided a positive effect when applied to AWM. With adequate design, by minimizing the release of ozone and particle re-entrainment, ESP can improve the quality of condensed water both in physical and chemical properties. Nevertheless, to ensure the sustainability of the condensed water quality produced by AWM according to the established standards, the addition of other filtration aids for both air and water is recommended.

\section{Acknowledgement}

This work was funded by the research grant from Ministry of Research and Technology of the Republic Indonesia/National Research and Innovation Agency No. 58.25.3/UN37/PPK.6.8/2021.

\section{References}

[1] Beysens, Daniel, and Irina Milimouk. "Pour des ressources alternatives en eau." Science et changements planétaires/Sécheresse 11, no. 4 (2001): 281-288.

[2] Gido, Ben, Eran Friedler, and David M. Broday. "Assessment of atmospheric moisture harvesting by direct cooling." Atmospheric Research 182 (2016): 156-162. https://doi.org/10.1016/i.atmosres.2016.07.029

[3] Ismail, A. M. M., N. A. S. Manssor, N. Amilin, A. Nalisa, I. Izyan, and N. Yahaya. "Dust Concentration in Office Environment." Journal of Advanced Research in Applied Mechanics 13, no. 1 (2015): 1-11.

[4] Yusoff, N. H. Mohamad, and C. S. Nor Azwadi. "Modelling of Flow Structure and Pollutant Dispersion in Symmetric Street Canyon." Journal of Advanced Research in Applied Mechanics 2, no. 1 (2014): 11-19.

[5] Afshari, Alireza, Lars Ekberg, Luboš Forejt, Jinhan Mo, Siamak Rahimi, Jeffrey Siegel, Wenhao Chen, Pawel Wargocki, Sultan Zurami, and Jianshun Zhang. "Electrostatic precipitators as an indoor air cleaner-a literature review." Sustainability 12, no. 21 (2020): 8774. https://doi.org/10.3390/su12218774

[6] de Oliveira, Alessandro Estarque, and Vádila Giovana Guerra. "Influence of particle concentration and residence time on the efficiency of nanoparticulate collection by electrostatic precipitation." Journal of Electrostatics 96 (2018): 1-9. https://doi.org/10.1016/j.elstat.2018.08.006

[7] Wen, Tsrong-Yi, Hsiu-Che Wang, Igor Krichtafovitch, and Alexander V. Mamishev. "Novel electrodes of an electrostatic precipitator for air filtration." Journal of Electrostatics 73 (2015): $117-124$. https://doi.org/10.1016/i.elstat.2014.11.002

[8] Porteiro, Jacobo, Rubén Martín, Enrique Granada, and David Patiño. "Three-dimensional model of electrostatic precipitators for the estimation of their particle collection efficiency." Fuel Processing Technology 143 (2016): 8699. https://doi.org/10.1016/j.fuproc.2015.11.010

[9] Xiao, Gang, Xihui Wang, Guang Yang, Mingjiang Ni, Xiang Gao, and Kefa Cen. "An experimental investigation of electrostatic precipitation in a wire-cylinder configuration at high temperatures." Powder Technology 269 (2015): 166-177. https://doi.org/10.1016/i.powtec.2014.08.063 
[10] Sander, Sören, Steffen Gawor, and Udo Fritsching. "Separating polydisperse particles using electrostatic precipitators with wire and spiked-wire discharge electrode design." Particuology 38 (2018): 10-17. https://doi.org/10.1016/j.partic.2017.05.014

[11] He, Zhongjie, and ET Mohan Dass. "Correlation of design parameters with performance for electrostatic precipitator. Part II. Design of experiment based on 3D FEM simulation." Applied Mathematical Modelling 57 (2018): 656-669. https://doi.org/10.1016/i.apm.2017.06.031

[12] World Health Organization. Guidelines for drinking-water quality. World Health Organization, 2017.

[13] Ministry of Health of Republic of Indonesia. "Peraturan Menteri Kesehatan Republik Indonesia Nomor 492 Tahun 2010. Persyaratan Kualitas Air Minum." Lembaran Negara Republik Indonesia, Kementerian Kesehatan Republik, Jakarta, Indonesia (2010).

[14] Jhunjhunwala, Sanket, Sumeet Sehrawat, and Kamlesh Pandey. "Performance Evaluation of a Three Stage Electrostatic Precipitation System for Collection of Particulate Matter Less Than PM2. 5." In 2018 International Conference on Communication and Signal Processing (ICCSP), pp. 0369-0371. IEEE, 2018. https://doi.org/10.1109/ICCSP.2018.8524565

[15] Hart, Julie F., Tony J. Ward, Terry M. Spear, Richard J. Rossi, Nicholas N. Holland, and Brodie G. Loushin. "Evaluating the effectiveness of a commercial portable air purifier in homes with wood burning stoves: a preliminary study." Journal of Environmental and Public Health 2011 (2011). https://doi.org/10.1155/2011/324809

[16] Zhang, Siyi, Wuxuan Pan, Hongsheng Zhang, Zhengwei Long, and Tao Yu. "High-efficient removal of airborne oil mist in a wire-plate electrostatic precipitator." Journal of Electrostatics 108 (2020): 103516. https://doi.org/10.1016/j.elstat.2020.103516

[17] Pirhadi, Milad, Amirhosein Mousavi, and Constantinos Sioutas. "Evaluation of a high flow rate electrostatic precipitator (ESP) as a particulate matter (PM) collector for toxicity studies." Science of the Total Environment 739 (2020): 140060. https://doi.org/10.1016/i.scitotenv.2020.140060

[18] Sander, Sören, and Udo Fritsching. "Dynamic flowsheet simulation of re-entrainment from particle layers formed inside electrostatic precipitators." Particuology 53 (2020): 41-47. https://doi.org/10.1016/i.partic.2019.12.009

[19] Zhou, Wenning, Renbao Jiang, Yifan Sun, Bing Chen, and Baiqian Liu. "Study on multi-physical field characteristics of electrostatic precipitator with different collecting electrodes." Powder Technology 381 (2021): $412-420$. https://doi.org/10.1016/i.powtec.2020.12.028

[20] Chen, Longwen, Evelyne Gonze, Michel Ondarts, Jonathan Outin, and Yves Gonthier. "Electrostatic precipitator for fine and ultrafine particle removal from indoor air environments." Separation and Purification Technology 247 (2020): 116964. https://doi.org/10.1016/j.seppur.2020.116964

[21] Dramane, Boni, Noureddine Zouzou, Eric Moreau, and Gérard Touchard. "Electrostatic precipitation in wire-tocylinder configuration: Effect of the high-voltage power supply waveform." Journal of Electrostatics 67, no. 2-3 (2009): 117-122. https://doi.org/10.1016/i.elstat.2009.01.022

[22] Viner, Andrew S., Phil A. Lawless, David S. Ensor, and Leslie E. Sparks. "Ozone generation in DC-energized electrostatic precipitators." IEEE Transactions on Industry Applications 28, no. 3 (1992): 504-512. https://doi.org/10.1109/28.137427

[23] Waring, Michael S., Jeffrey A. Siegel, and Richard L. Corsi. "Ultrafine particle removal and generation by portable air cleaners." Atmospheric Environment 42, no. $20 \quad$ (2008): 5003-5014. https://doi.org/10.1016/i.atmosenv.2008.02.011 